\title{
Tuberculosis in pediatric patients treated with anti-TNFa drugs: a cohort study
}

Joan Calzada-Hernández ${ }^{1}$, Jordi Anton-López', Rosa Bou-Torrent', Estíbaliz Iglesias-Jiménez', Sílvia Ricart-Campos', Javier Martín de Carpi², Carmen García de Vicuña Muñoz de la Nava ${ }^{3}$, Vicenç Torrente-Segarra', Judith Sánchez-Manubens ${ }^{1}$, Clara Giménez-Roca' ${ }^{1}$ Librada Rozas-Quesada ${ }^{4}$, Maria Teresa Juncosa-Morros ${ }^{5}$, Clàudia Fortuny ${ }^{6}$ and Antoni Noguera-Julian ${ }^{6 *}$

\begin{abstract}
Background: Adult patients receiving anti-TNFa drugs are at increased risk of tuberculosis (TB), but studies in pediatric populations are limited, and the best strategy for latent tuberculosis infection (LTBI) screening in this population remains controversial. We describe the prevalence of LTBI prior to anti-TNFa therapy and the long-term follow-up after biological treatment initiation in a cohort of children and adolescents.

Methods: Cohort observational study in children and adolescents receiving anti-TNFa agents in a tertiary-care pediatric hospital. LTBI was ruled out prior to the implementation of anti-TNFa drugs by tuberculin skin test (TST), and, from March 2012 on, QuantiFERON Gold-In Tube test (QTF-G). During anti-TNFa treatment, patients were evaluated every 6 months for TB with history and physical examination. TST/QTF-G were not repeated unless signs or symptoms consistent with TB arose or there was proven TB contact.

Results: The final cohort consisted of 221 patients (56.1\% female; 261 treatments), of whom 51.7\%/30.0 \%/17.3\% were treated with etanercept/adalimumab/infliximab, respectively, for a variety of rheumatic diseases (75.6\%), inflammatory bowel disease (20.8\%), and inflammatory eye diseases (3.6\%). The median (IQR) age at diagnosis of the primary condition was 6.8 years $(2.7-11.0)$ and the duration of the disease before implementing the anti-TNFa agent was 1.8 years (0.6-4.2). LTBI was diagnosed in 3 adolescent girls (prevalence rate: $1.4 \%$; 95 \% Cl: 0.4-4.2) affected with juvenile idiopathic arthritis: TST tested positive in only 1, while QTF-G was positive in all cases (including 2 patients already on etanercept). They all received antiTB chemoprophylaxis and were later (re)treated with etanercept for 24-29 months, without incidences. No incident cases of TB disease were observed during the follow-up period under antiTNFa treatment of 641 patients-year, with a median (IQR) time per patient of 2.3 years (1.4-4.3).

Conclusions: In our study, the prevalence of LTBI (1.4\%) was similar to that reported in population screening studies in Spain; no incident cases of TB disease were observed. In low-burden TB settings, initial screening for TB in children prior to anti-TNFa treatment should include both TST and an IGRA test, but systematic repetition of LTBI immunodiagnostic tests seems unnecessary in the absence of symptoms or known TB contact.
\end{abstract}

Keywords: Inflammatory bowel disease, Interferon-gamma release assays, Juvenile idiopathic arthritis, Tuberculosis, Anti-tumor necrosis factor-alpha drugs

\footnotetext{
* Correspondence: ton@hsjdbcn.org

${ }^{6}$ Pediatric Infectious Diseases Unit, Pediatrics Department, Hospital Sant Joan

de Déu, Universitat de Barcelona, Passeig Sant Joan de Déu 2, 08950

Esplugues de Llobregat, Spain

Full list of author information is available at the end of the article
} 


\section{Background}

Anti-tumour necrosis factor alpha (TNF $\alpha$ ) agents represent a major advance in the treatment of several autoimmune and autoinflammatory diseases, both in children and in adults. TNF $\alpha$ plays a critical role in the host response to tuberculosis (TB), having an essential role in the formation of the granuloma. Exposure to anti-TNF $\alpha$ drugs has been associated with reactivation of latent TB infection (LTBI) in adulthood, even after discontinuation of the treatment [1-3]. Therefore, current guidelines recommend screening for LTBI before anti-TNF $\alpha$ treatment implementation [2]. In children and adolescents on antiTNF $\alpha$ therapy, data are still scarce and questions about the best strategy for LTBI screening and the risk of TB remain unanswered [4].

Our aims were to assess the prevalence of LTBI in a cohort of children and adolescents expected to be treated with anti-TNF $\alpha$ agents and to describe the incidence of TB during follow-up while on anti-TNF $\alpha$ treatment.

\section{Methods}

We conducted a retrospective observational study in a large cohort of patients aged $<18$ years treated with antiTNF $\alpha$ agents for a variety of inflammatory diseases in a tertiary-care pediatric centre (Hospital Sant Joan de Déu, Barcelona) from December 2004 to January 2013, in Catalonia (Northeast Spain). The incidence rate of TB in Catalonia has decreased from 21.6 per 100,000 population in 2004 to 16.3 in 2012. Because anti-TNF $\alpha$ agents are hospital-prescribed drugs, patients were identified using centralized pharmacy records. Exclusion criteria were: 1. previous history of LTBI and/or TB; 2. previous exposure to anti-TNF $\alpha$ drugs; 3 . follow-up time $<3$ months since anti-TNF $\alpha$ drug implementation; and 4. anti-TNF $\alpha$ treatment first prescribed elsewhere. Patients for whom complete data on LTBI screening could not be retrieved were not included in the analysis of LTBI prevalence.

The following demographic and clinical variables were collected: age, gender, primary disease, time from diagnosis until start of anti-TNF $\alpha$ drug, and type and duration of anti-TNF $\alpha$ treatment. All patients are routinely screened for TB infection before anti-TNF $\alpha$ drug implementation. Our local protocol includes clinical history focused on TB risk (immigration from or travel to a high burden country for TB, known TB contacts, and signs or symptoms consistent with TB), Bacillus Calmette-Guérin (BCG) vaccine status, physical examination, tuberculin skin test (TST), and chest $x$-ray (CXR). A positive TST result is defined as a reaction $\geq 5 \mathrm{~mm}$ [5]. BCG vaccine is not recommended in Spain. As from March 2012, an IGRA (interferon-gamma release assays) test (Quantiferon-TB Gold-in Tube test, QTF-G; Cellestis, Carnegie, Australia) became available in clinical practice in our centre and was included in the screening protocol, together with TST.
After initial assessment, patients are clinically re-evaluated every 3-6 months for TB infection, but CXR and TST/ QTF-G are not routinely repeated in the absence of signs or symptoms consistent with $\mathrm{TB}$ or proven $\mathrm{TB}$ contact. In those patients with negative screening results before March 2012 who were still on anti-TNF $\alpha$ drugs later on, QTF-G was performed once during clinical follow-up. After exclusion of TB disease, any positive result is taken as evidence for LTBI and secondary chemoprophylaxis is recommended, as per national guidelines [5]. After 4 weeks of LTBI prophylaxis, anti-TNF $\alpha$ treatment is implemented if indicated. The local ethics committee approved the study. Categorical variables were described as percentages, and continuous variables as mean/standard deviation (SD) or median/interquartile ranges (IQR). Finally, we performed a systematic literature review to find original studies that evaluated anti-TNF $\alpha$ therapy in human subjects aged <18 years (English language, years 2000-2014). We reviewed all references found through PubMed using a combination of the search terms infliximab (INF), etanercept (ETN), adalimumab (ADA), and TB. We then checked the references of each study to find any missed studies.

\section{Results}

From December 2004, a total of 261 anti-TNF $\alpha$ treatments were prescribed to 221 patients (124 females, 97 males). Thirty-six patients switched once and two patients switched twice to other anti-TNF $\alpha$ drugs, mainly due to insufficient clinical response. The median (IQR) age at diagnosis of the primary condition was 6.8 (2.7-11.0) years and the duration of the disease before implementing the anti-TNF $\alpha$ agent was $1.8(0.6-4.2)$ years. Etanercept was the most commonly prescribed drug (51.7\%), followed by ADA (31.0\%) and INF (17.3\%). The total follow-up time while on anti-TNF $\alpha$ treatment was 614 patient-years; median time on anti-TNF $\alpha$ drug per patient was 2.3 (1.4-4.3) years (ETN 1.9 [1.8-3.7]; ADA $1.8[1.2-2.6]$; and INF $2.1[1.4-3.3]$ years). Juvenile idiopathic arthritis (JIA) was the most frequent indication for anti-TNF $\alpha$ treatment $(74.7 \%, 195$ treatments in 163 patients); other indications included inflammatory bowel disease $(19.1 \%, 50$ treatments in 46 patients) and idiopathic uveitis $(4.2 \%, 11$ treatments in 8 patients) (Table 1).

Most of the patients were Spanish (197 children, $89.1 \%)$. Among 16 patients from South America and 8 from Morocco, a BCG scar was documented in 13 and 4 children, respectively. Other than immigration from TBendemic regions, no other risk factors for TB were identified. Retrospective chart review documented no abnormal findings on CXR for 212 patients (95.9\%) and negative TST results in 209 children (94.6\%); positive TST was 
Table 1 Primary diseases leading to anti-TNFa treatment implementation; number (\%) of patients in all cases

\begin{tabular}{lll}
\hline Primary disease & $\begin{array}{l}\text { Patients } \\
(n=221)\end{array}$ & $\begin{array}{l}\text { Treatments } \\
(n=261)\end{array}$ \\
\hline Juvenile idiopathic arthritis & $163(73.6)$ & $195(74.7)$ \\
Polyarticular JIA, positive RF & $6(2.7)$ & $7(3.8)$ \\
Polyarticular JIA, negative RF & $40(18.1)$ & $48(18.4)$ \\
Oligoarticular JIA & $70(31.7)$ & $88(33.7)$ \\
Enthesitis-related arthritis & $24(10.9)$ & $24(9.2)$ \\
Psoriasic arthritis & $11(5.0)$ & $13(5.0)$ \\
Undifferentiated disease & $12(5.4)$ & $15(5.7)$ \\
Blau syndrome & $1(0.5)$ & $2(0.8)$ \\
Tumor necrosis factor associated & $1(0.5)$ & $1(0.4)$ \\
periodic syndrome & & $1(0.4)$ \\
PAPA syndrome & $1(0.5)$ & $1(0.4)$ \\
Chronic plantar fascitis & $1(0.5)$ & \\
Inflammatory bowel disease & & $39(14.9)$ \\
Crohn's disease & $36(16.3)$ & $11(4.2)$ \\
Ulcerative colitis & $10(4.5)$ & $10(3.8)$ \\
Inflammatory diseases of the eye & & $1(0.4)$ \\
Uveitis & $7(3.2)$ & \\
Pars planitis & $1(0.5)$ & \\
\hline
\end{tabular}

$J A$ juvenile idiopathic arthritis, PAPA pyogenic arthritis, pyoderma gangrenosum and acne, $R F$ rheumatoid factor

observed only in patient 3 (Table 2). Baseline CXR and TST results were not available for 9 and 11 patients, respectively.

From March 2012, QTF-G was performed in 75 patients $(33.9 \%)$, with positive, negative, and indeterminate results in 3 (patients $1-3$, Table 2), 66, and 6 children, respectively. Baseline TST was positive in just one of the 3 QTF-G positive patients, all of whom were BCGunvaccinated. All indeterminate QTF-G results were due to low mitogen response. Baseline screening results in these six patients (median [range] age: 8.6 [7.0-12.9] years) had previously ruled out LTBI and they were all on anti-TNF $\alpha$ treatment, associated with methotrexate in 4 cases. QTF-G was repeated in 4 of the 6 children with previous indeterminate result and proved negative in 3 of them, while remaining indeterminate in one. None of these patients received chemoprophylaxis nor developed TB after a median (IQR) follow-up of 1.8 $(1.6-1.9)$ years. The other two patients were transferred to adult care and were lost to follow-up.

Three Spanish girls affected with JIA were diagnosed with LTBI (prevalence rate: 1.4\%; 95 \% confidence interval: $0.4-4.2 \%$; Table 2). Focused history disclosed no known risk of TB infection in any of the girls; they had not received BCG vaccine and no clinical or radiological evidence of TB was detected. In patient 3, both TST and QTF-G tested positive before anti-TNF $\alpha$ or any other immunosuppressive drug was implemented. In patients 1 and 2, baseline TST was negative but QTF-G tested marginally positive afterwards, when ETN had already been implemented. When they were diagnosed with LTBI, the anti-TNF $\alpha$ treatment was discontinued and anti-TB chemoprophylaxis started, either 9 months of isoniazid monotherapy or 3 months of isoniazid and rifampicin. All patients adhered properly to the LTBI chemoprophylaxis regimen and no tolerability problems were reported. Etanercept was resumed 1 month after anti-TB chemoprophylaxis implementation; clinical follow-up while on ETN for 24, 25, and 29 months in patients 1,2 , and 3 , respectively, showed no evidence of TB reactivation. Overall, after a follow-up of 614 patient-years, no incident cases of TB disease were observed.

\section{Discussion}

In adults, anti-TNF $\alpha$ agents increase the risk of LTBI reactivation [1-3]. The risk has been described as being higher with monoclonal antibodies (INF/ADA), as compared with ETN, and times to TB onset from anti-TNF $\alpha$ drug implementation are shorter with INF (median time: 5.5 months) than with ETN (13.4 months) or ADA (18.5 months) [1]. In our pediatric cohort, patients received both monoclonal antibodies and ETN for a median time of 2.3 years per patient, and no incident TB disease cases were observed. Both the use of those drugs

Table 2 Details of the 3 girls affected with juvenile idiopathic arthritis that were diagnosed with latent tuberculosis infection and received antituberculosis chemoprophylaxis

\begin{tabular}{|c|c|c|c|c|c|c|c|}
\hline $\mathrm{Pt}$ & Age - gender - primary disease & $\begin{array}{l}\text { TST } \\
(\mathrm{mm})\end{array}$ & $\begin{array}{l}\text { Treatment at QTF-G } \\
\text { performance }\end{array}$ & $\begin{array}{l}\text { QTF-G IFN- } \gamma \\
\text { concentrations } \\
\text { (TB antigens-nil) } \\
\end{array}$ & $\begin{array}{l}\text { LTBI } \\
\text { chemoprophylaxis }\end{array}$ & $\begin{array}{l}\text { Maximum } \\
\text { ALT/AST } \\
(\mathrm{IU} / \mathrm{L}) \\
\end{array}$ & $\begin{array}{l}\text { Time on anti-TNFa drugs } \\
\text { (before/after LTBI } \\
\text { chemoprophylaxis) }\end{array}$ \\
\hline 1 & $\begin{array}{l}11 y 6 m \text { - female-polyarticular JIA, } \\
\text { negative RF }\end{array}$ & 0 & $\mathrm{ETN}+\mathrm{MTX}$ & $0.55 \mathrm{IU} / \mathrm{mL}$ & $\mathrm{H}$ for 9 months & $30 / 37$ & $22(1 / 24)$ months \\
\hline 2 & $\begin{array}{l}\text { 10y7m - female -oligoarticular } \\
\text { JIA }\end{array}$ & 0 & ETN & $0.37 \mathrm{IU} / \mathrm{mL}$ & HR for 3 months & $31 / 38$ & $29(14 / 25)$ months \\
\hline 3 & $8 y 5 m$ - female -oligoarticular JIA & 15 & NSAIDs & $4.78 \mathrm{IU} / \mathrm{mL}$ & HR for 3 months & $25 / 24$ & $12(0 / 29)$ months \\
\hline
\end{tabular}

$A L T$ alanine aminotransferase, AST aspartate aminotransferase, $H$ isoniazid, IFN- $\gamma$ interferon-gamma, MTX methotrexate, NSAIDs non-steroidal anti-inflammatory drugs, $P$ t patient, $R$ rifampicin, $R F$ rheumatoid factor 
with the higher risk and the long follow-up time in our cohort are reassuring.

A systematic review by Toussi et al. identified very few children on anti-TNF $\alpha$ drugs who developed TB [6], likely owing to a lower prevalence of LTBI in the pediatric age and to effective screening of LTBI. Table 3 summarizes all reported cases to date of mycobacterial disease in children and adolescents exposed to antiTNF $\alpha$ agents [3, 4, 7-14]. All cases involved extrapulmonary TB, and miliary/meningeal TB and death were reported in 5 and 2 patients (out of 11 cases), respectively. Of note, disease caused by non-TB mycobacterial species has also been reported after anti-TNF $\alpha$ drug use [13], and also following in utero exposure to infliximab [14].

To the best of our knowledge, this is the largest published cohort of patients aged $<18$ years treated with anti-TNF $\alpha$ agents in whom TB infection was investigated, both in terms of number of children and length of follow-up. The LTBI prevalence rate in our study (1.4\%) is similar to that reported in the healthy pediatric Spanish population (0.9 \%) [15], and, more importantly, no incident cases of TB disease were observed. The retrospective design, the low TB incidence in Catalonia, and the fact that QTF-G was unavailable until March 2012 are limitations of our study.

Similar studies from Turkey and England have been published [16-19]. In the Turkish studies, the reported prevalence rate for LTBI ranged from 4.8 to $19.4 \%$, and this was probably overestimated because of false-positive results due to universal BCG vaccination in Turkey [16-18]. In the English study, both TST and QTF-G were performed by INF treatment in 23 children, and only one case of LTBI was diagnosed [19]. All LTBI cases in these studies received chemoprophylaxis before anti-TNF $\alpha$ drug implementation, and no cases of TB were reported, highlighting the importance of LTBI diagnosis and treatment in this group of patients. In the absence of specific data on the best chemoprophylaxis regimen for LTBI in these patients, using the same regimens used in healthy children seems reasonable [5].

Table 3 Table summarizing cases published to date of mycobacterial disease in patients aged $<18$ years who were exposed to antiTNFa agents

\begin{tabular}{|c|c|c|c|c|c|c|}
\hline $\mathrm{Pt}$ & Ref & $\begin{array}{l}\text { Primary } \\
\text { disease }\end{array}$ & Anti-TNFa drug & $\begin{array}{l}\text { Age/ } \\
\text { gender }\end{array}$ & $\begin{array}{l}\text { Time } \\
\text { on } \\
\text { drug }\end{array}$ & Details on mycobacterial disease \\
\hline \multicolumn{7}{|c|}{ Tuberculosis disease } \\
\hline 1 & {$[3]$} & $\mathrm{JA}$ & Etanercept & NR & NR & Extrapulmonary \\
\hline 2 & [3] & $J \mathrm{~A}$ & Etanercept & NR & NR & Extrapulmonary \\
\hline 3 & {$[7]$} & $\begin{array}{l}\text { Polyarticular } \\
\text { JIA }\end{array}$ & Infliximab + MTX & NR & $2 y$ & $\begin{array}{l}\text { Asymptomatic miliary TB (MTB PCR positive in sputum) with good } \\
\text { response to 9-month standard treatment }\end{array}$ \\
\hline 4 & {$[8]$} & Systemic JIA & $\begin{array}{l}\text { Etanercept } \rightarrow \text { infliximab }+ \text { (previous } \\
\text { extensive immunosuppressive } \\
\text { therapy) }\end{array}$ & $\begin{array}{l}9 y / \\
\text { female }\end{array}$ & NR & $\begin{array}{l}\text { Subcutaneous cyst on the left wrist, after extensive microbiological } \\
\text { studies, only MTB PCR in cyst fluid was positive. The child died after } \\
\text { fulminant undiagnosed opportunistic pulmonary infection, } 1 \text { month } \\
\text { after anti-TB drugs were implemented }\end{array}$ \\
\hline 5 & [9] & Systemic JIA & Etanercept (previous CT and MTX) & $\begin{array}{l}9 y / \\
\text { female }\end{array}$ & $5 w k$ & $\begin{array}{l}\text { Ankle arthritis with positive MTB culture and normal chest X-ray; good } \\
\text { response to 12-month standard treatment }\end{array}$ \\
\hline 6 & {$[10]$} & $\begin{array}{l}\text { SAPHO } \\
\text { syndrome }\end{array}$ & Adalimumab (previous CT) & $\begin{array}{l}17 y / \\
\text { female }\end{array}$ & $3 y$ & $\begin{array}{l}\text { Meningeal and miliary TB presenting with septic shock; several PCR } \\
\text { and cultures tested positive for MTB. Good response to therapy, but } \\
\text { for neurologic sequelae. Adalimumab stopped } 4 \text { weeks earlier, } \\
\text { suggesting immune reconstitution inflammatory syndrome }\end{array}$ \\
\hline 7 & [11] & $\begin{array}{l}\text { Polyarticular } \\
\text { JIA }\end{array}$ & Infliximab (previous MTX) & $\begin{array}{l}13 y / \\
\text { male }\end{array}$ & $3 \mathrm{~m}$ & TB pleuritis (cultures negative) with good response to anti-TB therapy \\
\hline 8 & [12] & $\begin{array}{l}\text { Ulcerative } \\
\text { colitis }\end{array}$ & $\begin{array}{l}\text { Infliximab } \\
\text { (previous } C T \text { and azathioprine) }\end{array}$ & $\begin{array}{l}17 y / \\
\text { male }\end{array}$ & $8 \mathrm{~m}$ & $\begin{array}{l}\text { Miliary TB; the patient developed isoniazid-related hepatitis, but } \\
\text { showed good response later on to an isoniazid-free regimen }\end{array}$ \\
\hline 9 & [12] & $\begin{array}{l}\text { Crohn's } \\
\text { disease }\end{array}$ & Infliximab & $\begin{array}{l}13 y / \\
\text { female }\end{array}$ & $2 y$ & $\begin{array}{l}\text { Disseminated TB disease with good response to 9-month standard } \\
\text { therapy }\end{array}$ \\
\hline \multicolumn{7}{|c|}{ Nontuberculous mycobacterial disease } \\
\hline 10 & [13] & $\begin{array}{l}\text { Crohn's } \\
\text { disease }\end{array}$ & $\begin{array}{l}\text { Infliximab } \rightarrow \text { adalimumab } \\
\text { (previous } \mathrm{CT} \text { ) }\end{array}$ & $\begin{array}{l}12 y / \\
\text { female }\end{array}$ & $9 \mathrm{~m}$ & $\begin{array}{l}\text { Generalized lymphadenopathies due to culture-proven Mycobacterium } \\
\text { avium complex infection; good response to ethambutol, clarithromycin } \\
\text { and rifampin }\end{array}$ \\
\hline 11 & [14] & $\begin{array}{l}\text { Mother's } \\
\text { Crohn } \\
\text { disease }\end{array}$ & Infliximab during gestation & $\begin{array}{l}3 \mathrm{~m} / \\
\text { male }\end{array}$ & $\begin{array}{l}36 w k \\
\text { in } \\
\text { utero }\end{array}$ & $\begin{array}{l}\text { Bottle-fed. BCG vaccination at } 3 \mathrm{~m} \text { of age; disseminated BCGitis } \\
\text { leading to death } 6 \text { weeks later }\end{array}$ \\
\hline
\end{tabular}


The best way to screen for LTBI in these patients remains uncertain. Recent studies in adults with immunemediated inflammatory diseases have demonstrated that IGRA tests: a) show a better association with classic risk factors for LTBI; b) are more specific than TST for the diagnosis of LTBI, especially among BCG-vaccinated patients, and therefore decrease the number of LTBI treatments needed; and c) are more sensitive than TST, probably because they are less affected by concomitant use of corticosteroids or other immunosuppressive drugs [20, 21]. Despite this, significant numbers of patients with discordant positive TST/negative IGRA results in the absence of BCG vaccination have also been observed [21]. The latest expert recommendations call for a dual testing strategy including both TST and an IGRA test in immunosuppressed patients, or even a dual IGRA strategy in regions using BCG, in order to maximise sensitivity [22].

For the pediatric age data are still very scarce. In a large longitudinal series of children with inflammatory bowel disease (72 patients, 165 QTF-G tests), indeterminate QTF-G results (10 \%) were associated with corticosteroid use and several markers of disease activity, and 4. QTF-G conversions and 5 QTF-G reversions were identified during follow-up [23]. Similar rates of indeterminate IGRA results have been reported by other authors, and several cases of negative TST/positive IGRA and even negative/negative results in children with TB have been described $[10,19]$. Interestingly, in our cohort, LTBI in patients 1 and 2 was only diagnosed with borderline positive QTF-G results when both girls were already on ETN. While this may represent falsepositive results, it has also been reported that anti-TNF $\alpha$ therapy is associated with a higher rate of indeterminate IGRA results [23]. Given the lack of evidence, we are in agreement that both TST and at least one IGRA test should be used in immunosuppressed children, and any positive result should be taken as evidence of LTBI.

\section{Conclusions}

No incident cases of TB disease were observed after a 614 patient-year follow-up in a cohort of children and adolescents receiving anti-TNF $\alpha$ drugs in a lowincidence setting. Three girls $(1.4 \%)$ were diagnosed with LTBI; they received anti-TB chemoprophylaxis and did well upon ETN resumption. Tuberculosis does not seem to be a prevalent problem in our population, but severe evolution in the cases reported to date makes LTBI screening mandatory prior to anti-TNFo drug implementation. Although further data are needed to better define the optimal LTBI testing strategy in these children in low-burden TB settings, initial screening should include both TST and an IGRA test. However, systematic repetition of LTBI immunodiagnostic tests seems unnecessary in the absence of symptoms or known TB contact.

\section{Abbreviations}

ADA: Adalimumab; BCG: Bacillus Calmette-Guérin; CXR: Chest X-ray; ETN: Etanercept; IGRA: Interferon-gamma release assay; INF: Infliximab; JIA: Juvenile idiopathic arthritis; LTBI: Latent tuberculosis infection; QTFG: Quantiferon-TB gold-in tube test; TB: Tuberculosis; TNFa: Tumor necrosis factor alpha; TST: Tuberculin skin test.

\section{Competing interests}

The authors declare that they have no competing interests.

\section{Authors' contributions}

$\mathrm{JCH}$ participated in the design of the study, data collection, and data analysis, and drafted the manuscript. JAL, CFG, RBT, EIJ, VTS, JSM, CGR, JMC, CGVMN and SRC were responsible for clinical follow-up of the patients, and helped with data analysis and the drafting of the manuscript. MTJM and LRQ performed the immune diagnostics and also drafted the manuscript. ANJ conceived the study, participated in the design and data analysis, and drafted and supervised the manuscript. All authors read and approved the final version of the manuscript.

\section{Acknowledgements}

Joan Calzada-Hernández is the recipient of a grant Award "Moving4 niños con artritis" from the Sociedad Española de Reumatología Pediátrica (SERPE).

\section{Author details}

'Pediatric Rheumatology Unit, Pediatrics Department, Hospital Sant Joan de Déu, Universitat de Barcelona, Esplugues, Spain. ${ }^{2}$ Pediatric Gastroenterology Department, Hospital Sant Joan de Déu, Universitat de Barcelona, Esplugues, Spain. ${ }^{3}$ Ophthalmology Department, Hospital Sant Joan de Déu, Universitat de Barcelona, Esplugues, Spain. ${ }^{4}$ Unit for Control of Infectious Diseases, Hospital Sant Joan de Déu, Universitat de Barcelona, Esplugues, Spain. ${ }^{5}$ Microbiology Department, Hospital Sant Joan de Déu, Universitat de Barcelona, Esplugues, Spain. ${ }^{6}$ Pediatric Infectious Diseases Unit, Pediatrics Department, Hospital Sant Joan de Déu, Universitat de Barcelona, Passeig Sant Joan de Déu 2, 08950 Esplugues de Llobregat, Spain.

Received: 26 June 2015 Accepted: 29 November 2015

Published online: 03 December 2015

\section{References}

1. Tubach F, Salmon D, Ravaud P, Allanore Y, Goupille P, Bréban M, et al. Risk of tuberculosis is higher with anti-tumor necrosis factor monoclonal antibody therapy than with soluble tumor necrosis factor receptor therapy: The three-year prospective French Research Axed on Tolerance of Biotherapies registry. Arthritis Rheum. 2009;60:1884-94.

2. Ormerod LP, Milburn HJ, Gillespie S, Ledingham J, Rampton D. British Thoracic Society Standards of Care Committee. BTS recommendations for assessing risk and for managing mycobacterium tuberculosis infection and disease in patients due to start anti-TNF-alpha treatment. Thorax. 2005;60:800-5.

3. Mohan AK, Coté TR, Block JA, Manadan AM, Siegel JN, Braun MM. Tuberculosis following the use of etanercept, a tumor necrosis factor inhibitor. Clin Infect Dis. 2004:39:295-9.

4. Woerner A, Ritz N. Infections in children treated with biological agents. Pediatr Infect Dis J. 2013:32:284-8.

5. Moreno-Pérez D, Andrés Martín A, Altet Gómez N, Baquero-Artigao F, Escribano Montaner A, Gómez-Pastrana Durán D, et al. Diagnosis of tuberculosis in pediatrics. Consensus document of the Spanish Society of Pediatric Infectology (SEIP) and the Spanish Society of Pediatric Pneumology (SENP). An Pediatr (Barc). 2010. doi: 10.1016/j. anpedi.2009.12.017

6. Toussi SS, Pan N, Walters HM, Walsh TJ. Infections in children and adolescents with juvenile idiopathic arthritis and inflammatory bowel disease treated with tumor necrosis factor-a inhibitors: systematic review of the literature. Clin Infect Dis. 2013;57:1318-30.

7. Ruperto N, Lovell DJ, Cuttica R, Wilkinson N, Woo P, Espada G, et al. A randomized, placebo-controlled trial of infliximab plus methotrexate for the 
treatment of polyarticular-course juvenile rheumatoid arthritis. Arthritis Rheum. 2007:56:3096-106.

8. Armbrust W, Kamphuis SS, Wolfs TW, Fiselier TJ, Nikkels PG, Kuis W, et al. Tuberculosis in a nine-year-old girl treated with infliximab for systemic juvenile idiopathic arthritis. Rheumatology (Oxford). 2004;43:527-9.

9. Myers A, Clark J, Foster H. Tuberculosis and treatment with infliximab. N Engl J Med. 2002;346:623-6.

10. Hess S, Hospach T, Nossal R, Dannecker G, Magdorf K, Uhlemann F. Lifethreatening disseminated tuberculosis as a complication of TNF-a blockade in an adolescent. Eur J Pediatr. 2011;170:1337-42.

11. Kharbanda P, Dagaonkar R, Balakrishnan C, Udwadia ZF. Tumor necrosis factor-alpha blocker induced tuberculosis. J Rheumatol. 2010;37:1542.

12. Cruz AT, Karam LB, Orth RC, Starke JR. Disseminated tuberculosis in two children with inflammatory bowel disease receiving infliximab. Pediatr Infect Dis J. 2014;33:779-81.

13. Jordan N, Waghmare A, Abi-Ghanem AS, Moon A, Salvatore CM. Systemic mycobacterium avium complex infection during antitumor necrosis factor-a therapy in pediatric Crohn disease. J Pediatr Gastroenterol Nutr. 2012;54:294-6.

14. Cheent K, Nolan J, Shariq S, Kiho L, Pal A, Arnold J. Case report: Fatal case of disseminated BCG infection in an infant born to a mother taking infliximab for Crohn's disease. J Crohns Colitis. 2010;4:603-5.

15. Sacristán AM, Casares I, Lage MJ. Prevalencia de infección tuberculosa en adolescentes de 11 a 14 años en Palencia. Rev Pediatr Aten Primaria. 2004;6:9-17.

16. Ayaz NA, Demirkaya E, Bilginer Y, Ozçelik U, Cobanoğlu N, Kiper N, et al. Preventing tuberculosis in children receiving anti-TNFa treatment. Clin Rheumatol. 2010;29:389-92.

17. Cagatay T, Aydin M, Sunmez S, Cagatay P, Gulbaran Z, Gul A, et al. Followup results of 702 patients receiving tumor necrosis factor-a antagonists and evaluation of risk of tuberculosis. Rheumatol Int. 2010;30:1459-63.

18. Kilic O, Kasapcopur O, Camcioglu Y, Cokugras H, Arisoy N, Akcakaya N. Is it safe to use anti-TNF-a agents for tuberculosis in children suffering with chronic rheumatic disease? Rheumatol Int. 2012;32:2675-9.

19. Maritsi D, Al-Obadi M, Brogan PA, Eleftheriou D, Dixon GL. The performance of Quantiferon TB Gold in-Tube as a screening tool in paediatric rheumatology prior to initiation of infliximab: a single centre's experience. ISRN Rheumatol. 2011. doi: 10.5402/2011/505171.

20. Mariette X, Baron G, Tubach F, Lioté F, Combe B, Miceli-Richard C, et al. Influence of replacing tuberculin skin test with ex vivo interferon $y$ release assays on decision to administer prophylactic antituberculosis antibiotics before anti-TNFa therapy. Ann Rheum Dis. 2012;71:1783-90.

21. Kleinert S, Tony HP, Krueger K, Detert J, Mielke F, Rockwitz K, et al. Screening for latent tuberculosis infection: performance of tuberculin skin test and interferon- $\gamma$ release assays under real-life conditions. Ann Rheum Dis. 2012;71:1791-5

22. Winthrop KL, Weinblatt ME, Daley CL. You can't always get what you want, but if you try sometimes (with two tests-TST and IGRA-for tuberculosis) you get what you need. Ann Rheum Dis. 2012;71:1757-60.

23. Hradsky O, Ohem J, Zarubova K, Mitrova K, Durilova M, Kotalova R, et al. Disease activity is an important factor for indeterminate interferon- $\gamma$ release assay results in children with inflammatory bowel disease. J Pediatr Gastroenterol Nutr. 2014;58:320-4.

\section{Submit your next manuscript to BioMed Central and we will help you at every step:}

- We accept pre-submission inquiries

- Our selector tool helps you to find the most relevant journal

- We provide round the clock customer support

- Convenient online submission

- Thorough peer review

- Inclusion in PubMed and all major indexing services

- Maximum visibility for your research

Submit your manuscript at www.biomedcentral.com/submit
(O) BioMed Central 